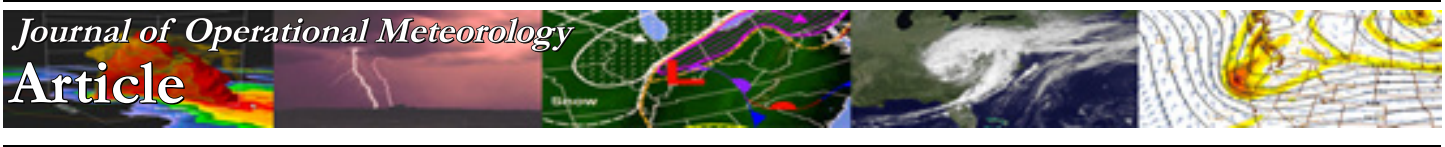

\title{
The Historic 2 April 2017 Louisiana Tornado Outbreak
}

\author{
ROBERT W. MEGNIA \\ National Weather Service, Lake Charles, Louisiana \\ TIMOTHY W. HUMPHREY \\ National Weather Service, Lake Charles, Louisiana \\ JARED A. RACKLEY \\ National Weather Service, Pittsburgh, Pennsylvania
}

(Manuscript received 2 October 2018; review completed 25 February 2019)

\begin{abstract}
On 2 April 2017 Louisiana saw one of its largest tornado outbreaks since 1950. The day saw a total of 21 tornadoes, six of which were classified as significant (EF2+). This extreme event resulted in an estimated 4.2 million dollars in damage and two fatalities. A climatology of Louisiana individual tornado days dating back to 1950 ranked this event second for total number of tornadoes (21) in a day and second for number of significant (EF2+) tornadoes (6) in a day. To assess the overall impact of this outbreak, the Destruction Potential Index (DPI) was used to compare both the overall number and strength of tornadoes to previous events. The 2 April 2017 event had the highest DPI for the state of Louisiana since 1950. Comparisons made to tornado days in nearby states in the region also highlight the significance of this event. The synoptic conditions of 2 April 2017 were compared to a 25 -member synoptic scale composite of past Louisiana tornado days with six or more tornadoes. The composite highlighted anomalies in synoptic ingredients that contribute to tornado outbreak environments. Most notably, the synoptic structure consisted of a more meridional flow pattern, which allowed for stronger moisture transport, low level shear, deep layer shear, and increased thermal advection. This produced an optimal mesoscale environment with high instability and storm-relative environmental helicity. The meteorological significance of this event with respect to Louisiana stems from the uncommon combination of a high shear/high CAPE near-storm environment in a southern tornado outbreak. The high shear/high CAPE environment largely responsible for the 2 April 2017 Louisiana tornado outbreak is more commonly observed in Great Plains tornado outbreaks.
\end{abstract}

\section{Introduction}

On 2 April 2017, the atmosphere had a synoptic scale setup that was optimal for severe weather in the state of Louisiana. The extreme conditions that were expected led the NOAA/NWS Storm Prediction Center (SPC) to issue a convective outlook that included the state of Louisiana in a High Risk for severe thunderstorms for the first time since 2005 (NOAA SPC 2017). Multiple tornadoes, some potentially strong, were forecast to occur within the High Risk area.

Twenty-one tornadoes, six of which were significant (EF2+), touched down between 12 UTC 2 April and 12 UTC 3 April 2017 in the state of Louisiana alone (Table
1). Three additional tornadoes touched down in Texas and one in Mississippi. The 21 tornadoes in Louisiana caused 4.2 million dollars' worth of damages and two fatalities. On average, 37 tornadoes occur annually within the state of Louisiana (NOAA SPC 2017). The 21 tornadoes that touched down on 2 April 2017 were more than half the state annual mean. Thus, this event should be reanalyzed and compared to past events to gain knowledge of its historical and meteorological significance. Additionally, we can compare this event to prior research that has attributed certain meteorological parameters and atmospheric setups to tornado outbreaks.

Previous research (Hagenmeyer 1997; Mercer et al. 2009, 2012; Tochimoto and Niino 2016, hereafter 
Table 1. 2 April 2017 tornadoes.

\begin{tabular}{|c|c|c|c|c|c|c|}
\hline Date & Time (UTC) & EF-Scale & Start Lat & Start Lon & End Lat & End Lon \\
\hline $4 / 2 / 2017$ & $2: 04: 00$ & 1 & 30.1641 & -92.0189 & 30.1649 & -92.0185 \\
\hline $4 / 2 / 2017$ & $2: 47: 00$ & 1 & 30.2676 & -91.8532 & 30.2756 & -91.8436 \\
\hline $4 / 2 / 2017$ & $7: 32: 00$ & 1 & 30.9925 & -92.5992 & 31.0748 & -92.5221 \\
\hline $4 / 2 / 2017$ & $19: 50: 00$ & 2 & 31.1255 & -92.5368 & 31.2138 & -92.5341 \\
\hline $4 / 2 / 2017$ & $19: 53: 00$ & 2 & 31.5788 & -92.2513 & 31.6561 & -92.2260 \\
\hline $4 / 2 / 2017$ & $20: 05: 00$ & 1 & 31.2499 & -92.4821 & 31.3281 & -92.4778 \\
\hline $4 / 2 / 2017$ & $20: 07: 00$ & 1 & 31.3077 & -93.5838 & 31.4000 & -93.4570 \\
\hline $4 / 2 / 2017$ & $20: 20: 00$ & 0 & 31.4595 & -92.7846 & 31.4605 & -92.7833 \\
\hline $4 / 2 / 2017$ & $20: 52: 00$ & 2 & 31.5115 & -92.2521 & 31.6977 & -92.1741 \\
\hline $4 / 2 / 2017$ & $20: 54: 00$ & 1 & 31.7815 & -92.5139 & 31.8155 & -92.4946 \\
\hline $4 / 2 / 2017$ & $21: 12: 00$ & 1 & 31.6917 & -92.8661 & 31.7449 & -92.8287 \\
\hline $4 / 2 / 2017$ & $21: 17: 00$ & 1 & 32.0597 & -91.9371 & 32.2308 & -91.8422 \\
\hline $4 / 2 / 2017$ & $21: 18: 00$ & 2 & 31.7476 & -92.1618 & 31.7627 & -92.1563 \\
\hline $4 / 2 / 2017$ & $21: 22: 00$ & 2 & 31.7365 & -92.0389 & 31.9045 & -91.9135 \\
\hline $4 / 2 / 2017$ & $21: 48: 00$ & 1 & 32.2377 & -91.8523 & 32.2669 & -91.8007 \\
\hline $4 / 2 / 2017$ & $21: 49: 00$ & 1 & 32.2603 & -91.7840 & 32.3110 & -91.7595 \\
\hline $4 / 2 / 2017$ & $21: 57: 00$ & 1 & 32.3110 & -91.7595 & 32.3243 & -91.7532 \\
\hline $4 / 2 / 2017$ & $22: 09: 00$ & 2 & 32.0870 & -91.6894 & 32.1534 & -91.6300 \\
\hline $4 / 2 / 2017$ & $22: 41: 00$ & 0 & 32.1898 & -91.4893 & 32.2089 & -91.4812 \\
\hline $4 / 3 / 2017$ & $9: 03: 00$ & 1 & 30.4400 & -90.2100 & 30.4442 & -90.1905 \\
\hline $4 / 3 / 2017$ & $9: 14: 00$ & 1 & 30.5265 & -90.0750 & 30.5295 & -90.0457 \\
\hline
\end{tabular}

TN16; Anderson-Frey et al. 2018, hereafter AF18) investigated characteristics in synoptic scale setups that can contribute to tornado outbreaks throughout the United States. Hagenmeyer (1997) used a simple averaging composite scheme to classify three types of tornado outbreaks for the Florida peninsula. With a more complex method, Mercer et al. (2012, hereafter M12) used rotated principal component analysis (RPCA) to create synoptic composites that distinguish tornadic outbreaks from non-tornadic outbreaks. More recently, TN16 and AF18 identified environmental characteristics that can be used to distinguish tornadic versus non-tornado outbreaks.

For this case study we will compare the 2 April 2017 tornado outbreak to a climatology of prior tornado outbreaks and highlight the anomalous magnitude of this particular event. With results from some of the aforementioned literature in mind, we will revisit this event from a synoptic perspective and determine which synoptic ingredients made the most significant contributions to the optimal mesoscale environment.
First, we compare 2 April 2017 to a climatology of tornado outbreaks for Louisiana and surrounding states. Second, we discuss a composite analysis of prior Louisiana tornado outbreaks followed by the synoptic and mesoscale features on 2 April 2017. After addressing synoptic differences between 2 April 2017 and prior events, we draw conclusions as to what separated this Louisiana tornado outbreak from prior ones.

\section{Overview and tornado report climatology}

This study uses tornado event data obtained from the SPC Severe Weather Database (Shaefer and Edwards 1999). This database contains the path length, maximum width, and maximum damage rating for each recorded tornado in the United States since 1950. Although this dataset is one of the most comprehensive records of tornadoes in the United States, there are many non-meteorological factors that affect the quality of the data. For example, studies have shown that population density influences the reporting rate of tornadoes 
(Verbout et al. 2006; Anderson et al. 2007). Changes in the methodology of assigning damage ratings also have introduced inconsistencies in the database that must be acknowledged when using it for research (Edwards et al. 2013).

For this case study, we use the SPC definition of a convective day as extending from 12 UTC to 12 UTC. Prior studies (Giordano and Fritsch 1991; Rogers et al. 2016) have shown that there is a peak in observed tornadoes between 19 and 00 UTC, which coincides with the time of peak diurnal heating. However, Krocak and Brooks (2018) demonstrate that the probability of tornadoes across the southeastern United States remains relatively high during overnight hours. Thus, by using the 12 UTC-12 UTC period we hope to capture the full time range during which tornadoes occur in the state of Louisiana.

Determining the significance of a tornado outbreak can be difficult given the fact that two similar tornadoes can have very different societal impacts. An outbreak of eight tornadoes in a sparsely populated region may not be considered as significant as a similar outbreak in a densely populated region even though the meteorology behind the two events is similar. There are several methods for ranking the significance of tornado outbreaks that include: ranking by number of tornadoes, number of significant tornadoes, and tornado fatalities (Doswell et al. 2006). Rather than choosing one method, we use three ranking methods that address meteorological significance and potential life and property threat to highlight the significance of the 2 April 2017 tornado outbreak.

The first two methods ranked tornado days by number of tornadoes in a day and number of significant tornadoes $(\mathrm{EF} 2 / \mathrm{F} 2+)$ in a day. The third method ranked Louisiana tornado events by Destruction Potential Index (DPI) (Thompson and Vescio 1998). DPI is a method used to rank tornado outbreaks based on both the intensity and damage path associated with an outbreak of tornadoes. This method was created in order to address both the life and property threat and the meteorological significance associated with tornadoes (Thompson and Vescio 1998). DPI is calculated with the following formula:

$$
D P I=\sum_{i=1}^{\mathrm{n}} a_{i}\left(F_{i}+1\right)
$$

where $n$ is the number of tornadoes in the outbreak, a is the area of the damage path, which for this study is computed using the length and maximum width of individual tornado tracks as measured from an NWS storm survey, and $F$ is the (E)F scale rating for each tornado. One is added to the (E)F scale rating to avoid values of 0 in the case of (E)F0 tornadoes.

The DPI was calculated for each Louisiana tornado recorded in the SPC Severe WeatherDatabase. Therefore, it is important to consider how the reporting biases inherent in the database can affect the interpretation of DPI. First, the EF scale is not an intensity scale but rather a damage scale (Doswell and Burgess 1988). Simmons and Sutter (2011) found a significant correlation between the frequency of EF2+ tornadoes and population density. This is likely due to buildings constituting the majority of damage indicators for EF2+ tornadoes. Anderson et al. (2007) also note that in rural areas EF2 + tornadoes have been likely underestimated on the EF scale. These findings would suggest that the EF rating and resultant DPI could be underestimated in rural areas. However, tornadoes being assigned an EF scale rating based on the maximum observed damage also can lead to an overestimation of the total damage observed along the path length and inflate the DPI. Similarly, using the maximum width likely inflates the DPI by overestimating the total area affected by the tornado. These biases can potentially reduce accuracy in DPI for individual tornadoes. However, the total DPI of outbreaks should be less susceptible to the inflation of EF0 and EF1 tornadoes when ranking events compared to raw counts of tornadoes. This is because the majority of these weak tornadoes tend to affect smaller total areas (Verbout et al. 2006; Anderson et al. 2007).

Figures 1 and 2 reveal the top ten tornado days and top ten significant tornado days, respectively, in Louisiana since 1950. 2 April 2017 ranks as the second largest tornado day with 21 tornadoes, trailing only the 31 October 2018 event that produced 22 tornadoes. For significant tornado days, 2 April 2017 ranks third along with five other dates with six tornadoes. These events trail only the 21 November 1992 and 19 May 1983 outbreaks that produced nine and seven significant tornadoes, respectively. When ranking tornado days in Louisiana by DPI, 2 April 2017 ranked highest with a DPI of 147.4 (Fig. 3). This is about 30 DPI units higher than the second ranked event, which produced a DPI of about 118 on 31 October 2018. Altogether, the three metrics provide an argument for ranking 2 April 2017 as the largest tornado outbreak in Louisiana history.

Cumulative distribution functions (CDFs) of these three metrics were compared to determine how rare the 2 April 2017 event is relative to tornado events in 


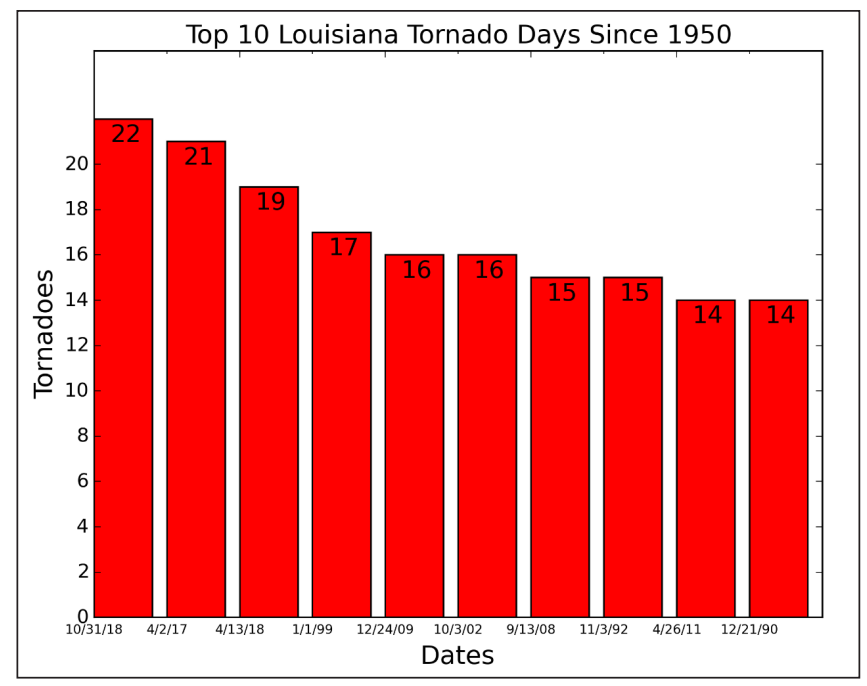

Figure 1. Bar graph of the top 10 Louisiana tornado days since 1950. Numbers embedded in each bar represent the bar value. Click image for an external version; this applies to all figures hereafter.

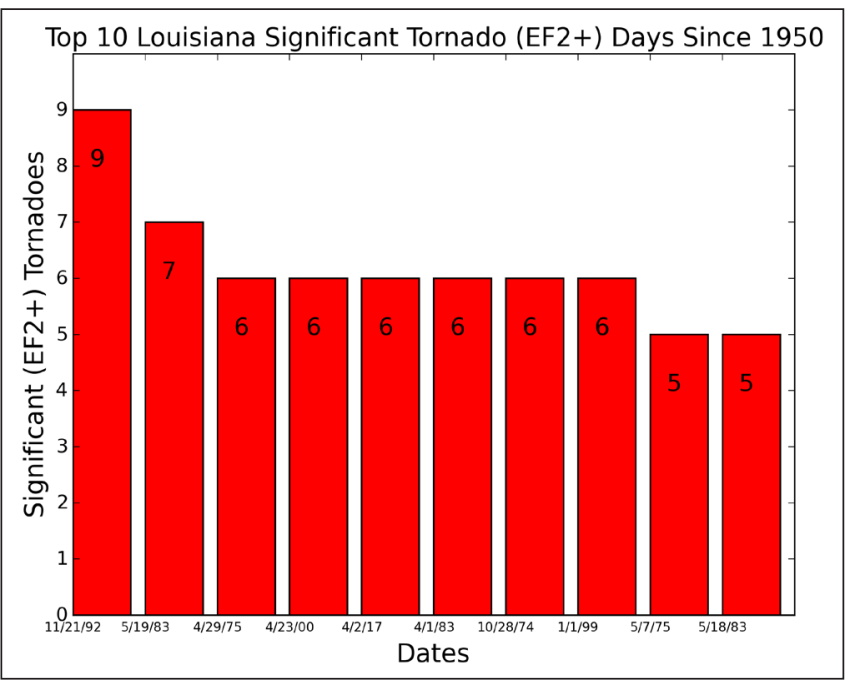

Figure 2. As in Fig.1 but for Significant Tornadoes.

nearby states. Six surrounding states in the region that are in close proximity to Louisiana (Alabama, Arkansas, Mississippi, Oklahoma, Tennessee, and Texas) were subjectively chosen for the regional analysis. To account for differences in state size, the counts per state were normalized to be per $25,000 \mathrm{~km}^{2}$. The CDFs describe the frequency of days in which a number of tornadoes, a number of significant tornadoes, and a range of DPI values each occur per $25,000 \mathrm{~km}^{2}$ within a state in a 24-h period. Only dates with two or more tornadoes were considered for the CDFs in order to ensure that the events being ranked were driven primarily by the synoptic/mesoscale environments rather than isolated

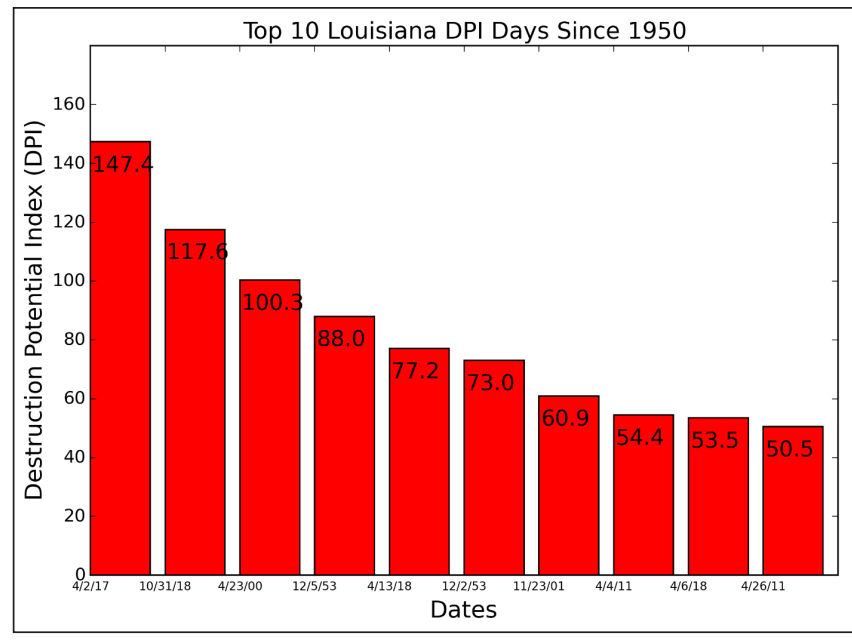

Figure 3. As in Fig.1, but for destruction potential index (DPI).

incidents.

Since 1950, an average of three or more tornadoes per $25,000 \mathrm{~km}^{2}$ occurring within any of the seven states in a day has only occurred 46 times. This ranks the 2 April 2017 event in the 99th percentile for tornadoes per $25,000 \mathrm{~km}^{2}$ (3.9) in a day since 1950 for the analyzed region (Fig. 4). This means that less than $1 \%$ of tornado days within the region produced 3.9 tornadoes per $25,000 \mathrm{~km}^{2}$. Similar analyses of significant tornadoes per $25,000 \mathrm{~km}^{2}$ in a day and DPI per 25,000 km² rank 2 April 2017 in the 98th and 99th percentiles, respectively, for this region (Figs. 5-6). These climatological statistics indicate that 2 April 2017 was a historic tornado outbreak for both the state of Louisiana and the surrounding region. This historical significance provided the motivation to perform further research to better understand the meteorological significance behind this event.

\section{Synoptic and mesoscale features}

\section{a. Louisiana tornado outbreak composite analysis}

Comparing the synoptic environment of 2 April 2017 to synoptic environments associated with prior tornado outbreaks in Louisiana can help identify anomalies in synoptic ingredients that contributed to the anomalous magnitude of the outbreak. To make this comparison, NAM analysis data from prior Louisiana tornado outbreaks were used to construct synoptic composites. What constitutes a tornado outbreak has been debated in past studies. Galway (1977) and AF18 characterize a tornado outbreak by having 10 or more 


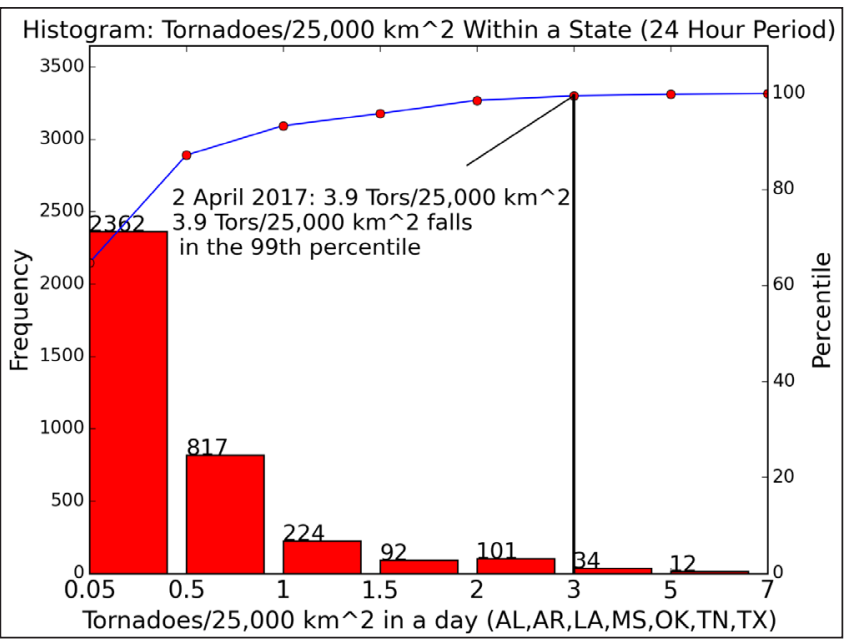

Figure 4. Histogram for a number range of tornadoes per 25 square $\mathrm{km}$ occurring within a state in a 24 hour period. Blue line represents the percentile that each bin falls in for the data set.

tornadoes. Pautz (1969) classified outbreaks on scales of small (6-10 tornadoes), moderate (11-20 tornadoes), and large ( $>20$ tornadoes). Ultimately, no formal definition of what constitutes a tornado outbreak will be appropriate in all cases. Therefore, it is preferable to use more subjective definitions that are determined based on the scientific objectives of the research in question (Doswell et al. 2006; AF18). In this case study, we used the Pautz (1969) definition of a tornado outbreak as at least 6 tornadoes occurring during a tornado day in order to attain the largest possible sample size from the period of the NAM dataset (2004-present). This definition yielded 25 tornado outbreaks to be included in the composite (Table 2). NAM analyses at the model initialization hour prior to the time at which the majority of tornadoes occurred in each of the 25 events were used to generate the composite. This was done to ensure the analyses were most representative of the prestorm environment.

A caveat of a composite analysis using a simple averaging technique is that phase differences in key synoptic features such as the position of upper-level trough axes and upper-level flow patterns can cause smearing. For example, if half the composite members are events dominated by northwesterly flow while the other half are events dominated by southwesterly flow, the average of these members would yield a composite with westerly flow, which would not be truly representative of a typical outbreak environment. To ensure the quality of this methodology, each of the individual composite members were examined to

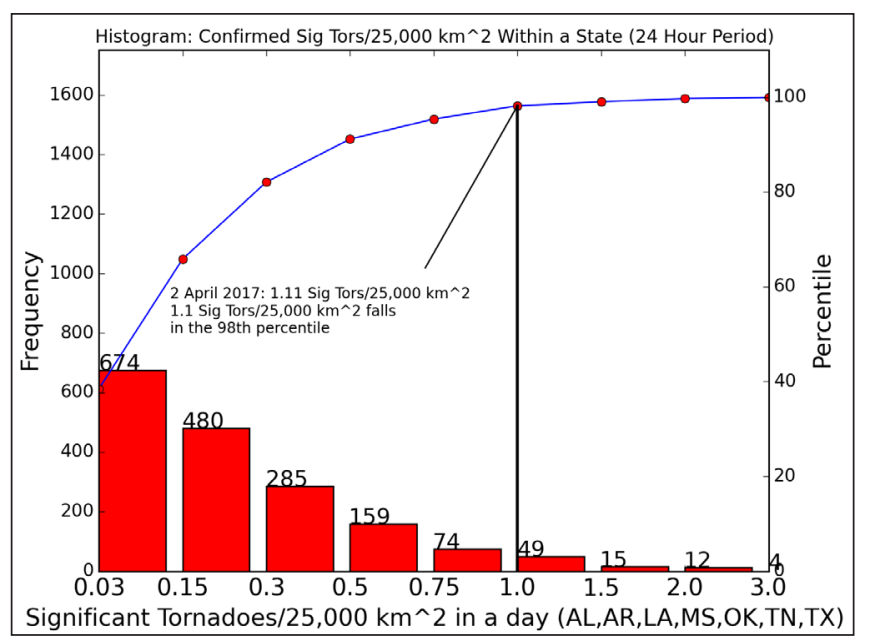

Figure 5. As in Fig.4, but for significant tornadoes. This histogram/CDF is based on tornado days with at least 1 $\mathrm{EF} 2+$ tornado.

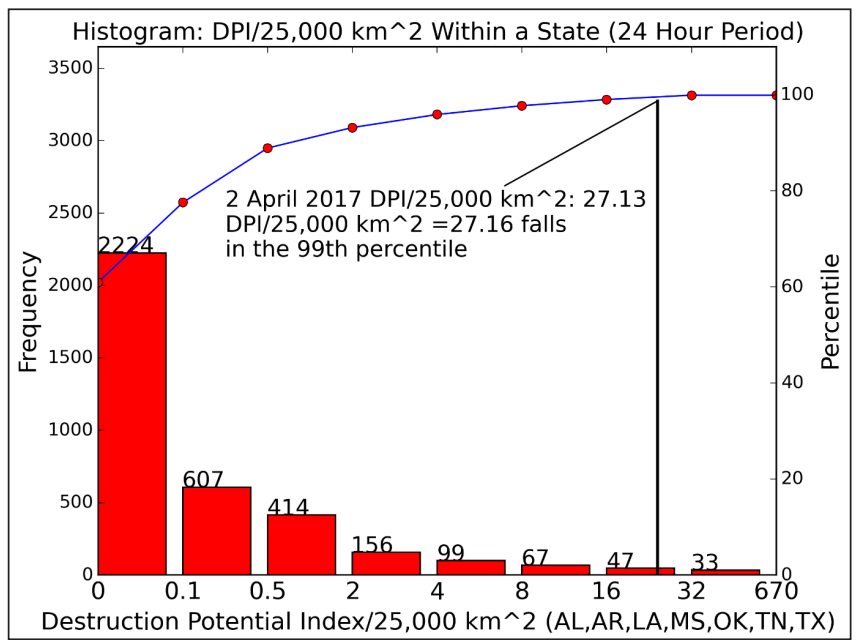

Figure 6. As in Fig.4, but for destruction potential index (DPI).

determine if the composite average presents a realistic representation of a typical Louisiana tornado outbreak event. Each composite member was classified by the dominant flow pattern that drove each event.

In Table 3, each event used in the composite analysis is listed with its associated flow pattern. The events were dominated by southwesterly flow regimes at upper levels with trough axes located to the west. Two outliers were the 6 April 2018 and 7 February 2017 events that were dominated by northwesterly and westnorthwesterly flow aloft, respectively. With 23 of the 25 events having similar synoptic setups with respect to flow regime, we do not expect composite smearing from phase differences to be an issue in our composite analysis. Therefore, the composite average of the 25 
Table 2. Louisiana tornado outbreak days (six or more tornadoes) selected for composite analysis.

\begin{tabular}{|c|c|}
\hline Louisiana Tornado Outbreak Dates & Louisiana Tornado Outbreak Dates \\
\hline 23-Nov-04 & 25-Jan-12 \\
\hline 16-Oct-06 & 21-Mar-12 \\
\hline 13-Feb-07 & 25-Dec-12 \\
\hline 12-Feb-08 & 31-Oct-13 \\
\hline 16-Feb-08 & $23-F e b-16$ \\
\hline 15-May-08 & 2-Jan-17 \\
\hline 9-Apr-09 & 21-Jan-17 \\
\hline 22-Oct-09 & 7-Feb-17 \\
\hline 29-Oct-09 & 28-Mar-18 \\
\hline 24-Dec-09 & 6-Apr-18 \\
\hline $25-N o v-10$ & 13-Apr-18 \\
\hline 4-Apr-11 & 31-Oct-18 \\
\hline 26-Apr-11 & \\
\hline
\end{tabular}

Table 3. Composite member dominant flow patterns.

\begin{tabular}{|c|c|c|c|}
\hline Composite Member & Flow Regime & Composite Member & Flow Regime \\
\hline 23-Nov-04 & SW & 25-Jan-12 & SSW \\
\hline 16-Oct-06 & SW & 21-Mar-12 & SSW \\
\hline $13-$ Feb-07 & SW & 25-Dec-12 & SW \\
\hline $12-F e b-08$ & SW & 31-Oct-13 & SW \\
\hline 16-Feb-08 & SW & 23-Feb-16 & SW \\
\hline 15-May-08 & SW & 2-Jan-17 & SW \\
\hline 9-Apr-09 & WSW & 21-Jan-17 & SW \\
\hline 22-Oct-09 & SW & 7-Feb-17 & WNW \\
\hline 29-Oct-09 & SW & 28-Mar-18 & SW \\
\hline 24-Dec-09 & SW & 6-Apr-18 & NW \\
\hline $25-$ Nov-10 & SW & 13-Apr-18 & SW \\
\hline 4-Apr-11 & SW & 31-Oct-18 & SW \\
\hline 26-Apr-11 & SW & & \\
\hline
\end{tabular}

selected events should be reasonably representative of a typical Louisiana tornado outbreak.

From the synoptic outbreak composite (Fig. 7), we can make some generalizations about synoptic scale setups that can produce a Louisiana tornado outbreak. Above $500 \mathrm{hPa}$, there tends to be a trough centered over the Central Plains and a ridge over the eastern United States (Fig. 7 a, b). Louisiana lies east of the trough axis beneath the exit/entrance regions of a coupled jet streak structure. Beneath the coupled jets, there is an elongated $850 \mathrm{hPa}$ trough centered over the Oklahoma/ Texas border. This is consistent with TN16, which demonstrates that extra tropical cyclones (ECs) that produce warm sector tornado outbreaks tend to have more elongated flow patterns associated with strong anticyclonic shear in associated jet streaks. The more elongated flow pattern results in stronger meridional winds which enhances both moisture transport and lowlevel shear. This elongated flow contributed to the large values of integrated water vapor transport (IVT) over Louisiana in Fig. 7c and large values of $0-1 \mathrm{~km}$ shear over Louisiana in Fig. 7d.

MSLP and height analyses on 2 April 2017 are overlaid by shaded anomalies relative to the tornado 


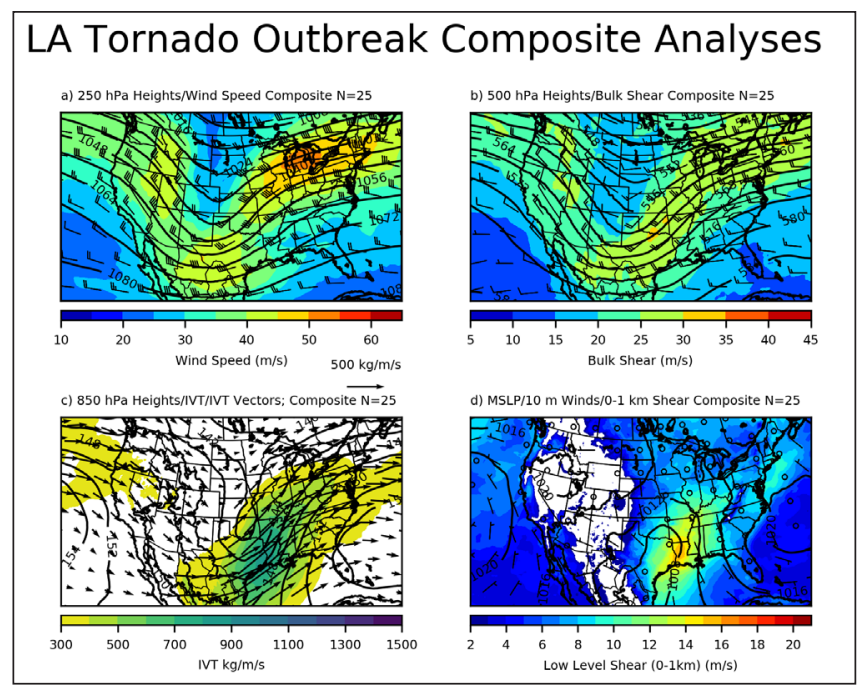

Figure 7. Composite average fields derived from NAM Analyses data of 25 Louisiana tornado outbreak days. a). $250 \mathrm{hPa}$ height (dam) contours, $250 \mathrm{hPa}$ wind barbs $(\mathrm{m} / \mathrm{s}), 250 \mathrm{hPa}$ wind speed shaded $(\mathrm{m} / \mathrm{s})$. b). $500 \mathrm{hPa}$ height (dam) contours, 0-6 km wind shear barbs $(\mathrm{m} / \mathrm{s})$, 0-6 km wind shear shaded (m/s). c). $850 \mathrm{hPa}$ height (dam) contours, IVT vectors $(\mathrm{kg} / \mathrm{m} / \mathrm{s})$, IVT $(\mathrm{kg} / \mathrm{m} / \mathrm{s})$ (shaded). d). MSLP ( $\mathrm{hPa}$ ) isobars, 10 meter wind barbs $(\mathrm{m} / \mathrm{s})$, and $0-1 \mathrm{~km}$ wind shear (shaded).

outbreak composite to visualize the differences between the Fig. 7 composite and the conditions on 2 April. Figures $8 \mathrm{a}-8 \mathrm{~d}$ reveal positive anomalies in jet stream strength, 0-6 km bulk shear, IVT, and 0-1 km bulk shear, respectively. The positive anomalies in the jet-stream are observed at the base of the $250 \mathrm{hPa}$ trough over Mexico. Positive anomalies in $0-6 \mathrm{~km}$ bulk shear, IVT, and $0-1 \mathrm{~km}$ shear are observed over central Louisiana. The positive anomalies in each of these parameters can contribute to an environment favorable for tornado outbreaks. A strong jet streak and associated anticyclonic shear can enhance IVT, $0-6 \mathrm{~km}$ bulk shear, and $0-1 \mathrm{~km}$ bulk shear. The impacts of these parameters on tornadogenesis are discussed in further detail in the following sections.

The anomalies on 2 April 2017 relative to the Fig. 7 composite indicate that conditions were more favorable than the typical synoptic environment that produces tornado outbreaks in Louisiana. In order to determine the significance of these positive anomalies and the contributions they made to the outbreak environment, we now analyze the evolution of both the synoptic and mesoscale environments on 2 April 2017.

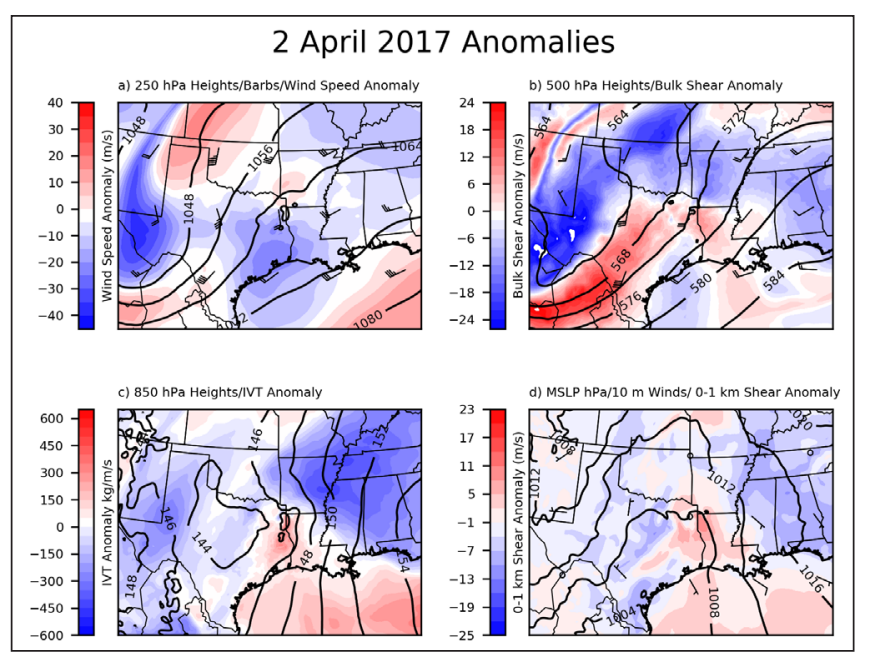

Figure 8. 2 April 2017 anomalies relative to Fig. 7 composite. As in Fig. 7 (no IVT vectors).

\section{b. 2 April 2017 synoptic analysis}

Rapid Refresh (RAP) model data are used to analyze the synoptic scale setup of the 2 April 2017 Louisiana tornado outbreak. Whereas model analyses do not represent the true atmosphere, past studies demonstrate that they are a sufficient proxy (Thompson 1998; Thompson et al. 2003, herein T03; Schumacher et al. 2010; Grams et al. 2012). The RAP was chosen as the primary data source for its high spatial $(13 \mathrm{~km})$ and temporal (1-h) resolution. Though using the same model data for the synoptic, mesoscale, and composite analyses would be optimal, NAM model data were selected for the composite analysis because of the model's high resolution and period of record extending back to 2004. Even though RAP model data only dates back to 2012, the hourly temporal resolution was deemed critical in being able to thoroughly analyze the evolution of the synoptic and mesoscale environment on 2 April 2017.

Figure 9 provides an animation for the evolution of the synoptic scale setup between 12 UTC 2 April 2017 and 12 UTC 3 April 2017. The synoptic setup was similar to the composite of Louisiana tornado outbreaks. A positively tilted upper-level trough was located over Texas and Mexico, with a jet streak centered at the base of the trough (Fig. 9a). The trough transitioned to a neutral/negative tilt as the day progressed. The strength of the jet streak and the tight geopotential height gradient contributed to enhanced anti-cyclonic shear on the poleward side of the jet streak. This had a significant influence on the environment as significant anticyclonic shear in jet streaks produces more meridionally 


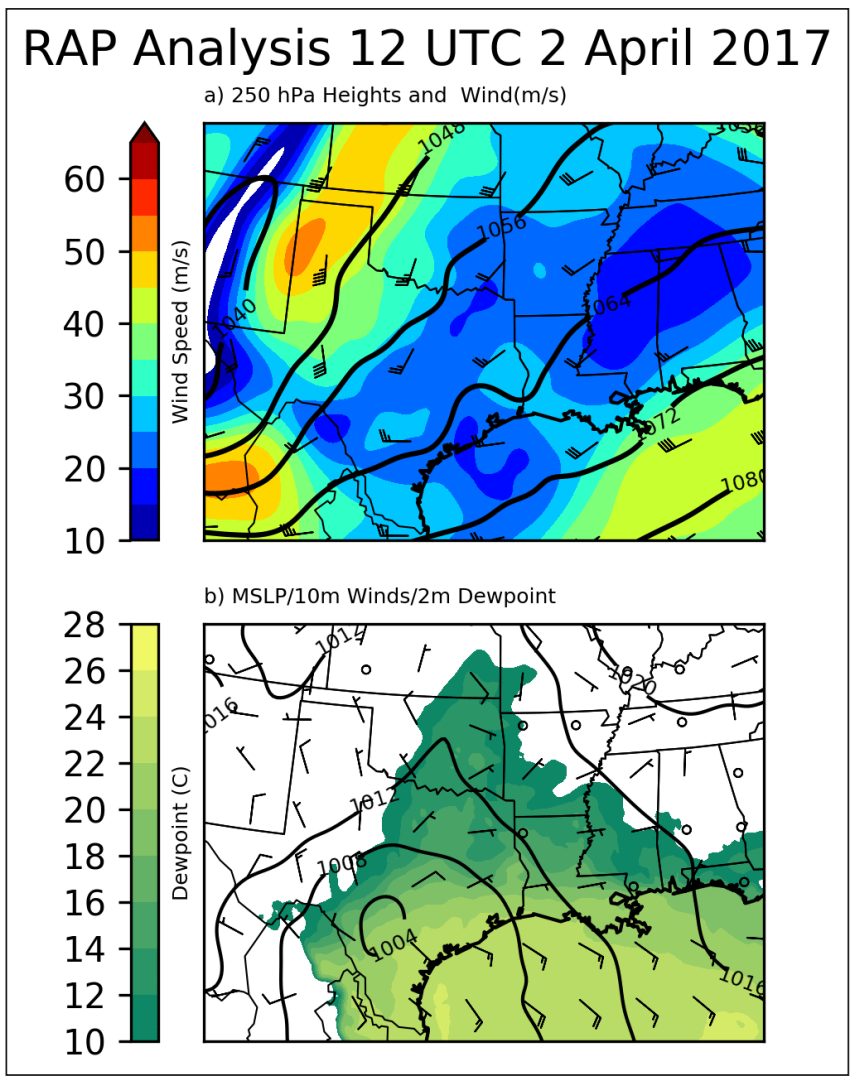

Figure 9. RAP Analysis 12 UTC 2 April 2017 - 12 UTC 3 April 2017. a). As in Fig. 7a. b). MSLP (hPa) black contours, $10 \mathrm{~m}$ wind barbs (m/s), and $2 \mathrm{~m}$ dewpoint (C) (shaded). Click for animation.

elongated ECs (Davies et al. 1991; Wernlie et al. 1998; Shultz et al. 1998; Schultz and Zhang 2007).

At the surface, the primary feature in the MSLP field was an inverted trough over east Texas (Fig. 9b). The low pressure center was located below the exit region of the associated upper level jet streak. As the day progressed, diffluent flow aloft and anticyclonic shear contributed to both the surface trough becoming more meridionally elongated and the surface cyclone strengthening. This resulted in surface winds increasing from $5 \mathrm{~m} / \mathrm{s}(\sim 10 \mathrm{kt})$ at $12 \mathrm{UTC}$ to $10 \mathrm{~m} / \mathrm{s}(\sim 20 \mathrm{kt})$ at 20 UTC. The elongated structure of the EC and subsequent increase in near-surface southerly winds contributed to the tornado outbreak environment in the way of increased destabilization via moisture transport, increased vertical shear, and increased thermal advection, which acted as a source of lift in the warm sector. This is evident from the surge of surface dewpoint temperatures (Fig. 9b), IVT, and warm temperature advection over central Louisiana at the same time the synoptic structure elongates meridionally (Fig. 10) and the surface winds strengthen. These patterns are consistent with previous findings in TN16 and M12 composite analyses for tornado outbreak environments.

\section{c. 2 April 2017 mesoscale analysis}

RAP model data are used to evaluate the evolution of near-storm environmental parameters on 2 April 2017. Four mesoscale parameters are analyzed to assess the favorability of an environment supportive of tornadogenesis: mixed-layer CAPE (MLCAPE), 0-6 $\mathrm{km}$ bulk shear, 0-1 km SRH, and mixed-layer LCL height (MLLCL). Past studies (i.e., Rasmussen and Blanchard 1998; Thompson et al. 2003; Craven and Brooks 2004; Garner 2012) have shown a tendency for greater frequency of tornadogenesis when certain thresholds of these parameters are met. Larger values of MLCAPE contribute to tornadogenesis in the form of supporting strong updrafts that can tilt and subsequently stretch horizontal vorticity (Davies-Jones

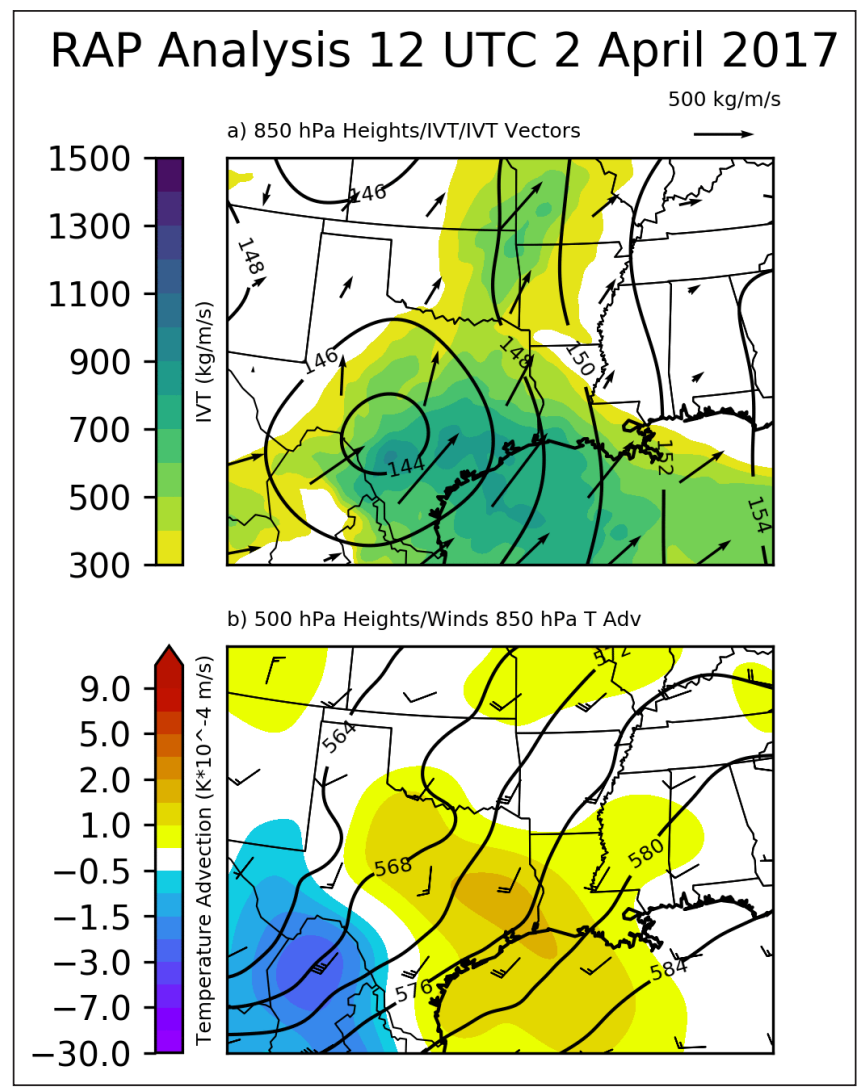

Figure 10. RAP Analysis 12 UTC 2 April 2017 - 12 UTC 3 April 2017. a). As in Fig. 7c b). 500 hPa heights (dam) black contours, $500 \mathrm{hPa}$ wind barbs $(\mathrm{m} / \mathrm{s})$, and Gaussian filtered $850 \mathrm{hPa}$ temperature advection $\mathrm{K}^{*} 10^{-4}$ $/ \mathrm{m} / \mathrm{s}$ (shaded). Click for animation. 
1984). Larger deep-layer shear is a necessary ingredient for tornadogenesis as it helps remove rain from the updraft and also induces vertical perturbation pressure gradients that increase updraft strength (Rotunno and Klemp 1982). Stronger low-level shear lowers the base of the mid-level mesocyclone, which promotes strong dynamic lifting of near surface air (Markowski and Richardson 2014). Lower MLLCL heights reduce the potential for evaporation, which promotes warmer rear flank downdrafts (RFDs) with greater potential buoyancy (Markowski et al. 2002).

The significant tornado parameter (STP; T03) is a parameter derived from the aforementioned near-storm environmental parameters. STP values $>1$ have been shown to be a good discriminator between non-tornadic and significantly tornadic supercell environments (T03). STP is computed with the following equation:

$\mathrm{STP}=(\mathrm{MLCAPE} / 1000) *((2000-\mathrm{MLLCL}) / 1500) *(\mathrm{SRH}$ /100)*(SHEAR6KM/20)*((200+MLCIN)/150)

where SRH is calculated over the $0-1 \mathrm{~km}$ layer and SHEAR6KM is the bulk shear in the $0-6 \mathrm{~km}$ layer. Traditionally, STP is calculated with the SRH and SHEAR terms derived from an effective layer parcel. However, $0-1 \mathrm{~km}$ SRH and $0-6 \mathrm{~km}$ bulk shear are substituted for these parameters due to lack of effective layer parameters in the RAP dataset and the high computational expense of manually deriving effective layer parameters.

We use STP and its associated parameters to analyze the evolution of the mesoscale environment on 2 April 2017. STP is analyzed to assess the overall favorability of the environment, while each of its parameters are analyzed to see the evolution of each variable and its contribution to the environment. Figure 11 provides an animation of the evolution of these parameters and the mesoscale environment on 2 April 2017. Additionally, tornado symbols are plotted in the animations at the hour before the tornado was recorded. This is done to assess the relationship between the time each tornado occurred and the mesoscale environment at that time.

Between 14 and 15 UTC on 2 April 2017, the first two tornadoes of the outbreak were recorded in Lafayette Parish in south central Louisiana. At this time, instability, low level helicity, and $0-6 \mathrm{~km}$ bulk shear were high, with values of around $2500 \mathrm{~J} / \mathrm{kg}, 200+$ $\mathrm{m}^{2} / \mathrm{s}^{2}$, and $25 \mathrm{~m} / \mathrm{s}$, respectively (Fig. 11a). MLLCL heights were low over the location of the first two tornadoes ranging from $300-400 \mathrm{~m}$ with $0-1 \mathrm{~km}$ bulk

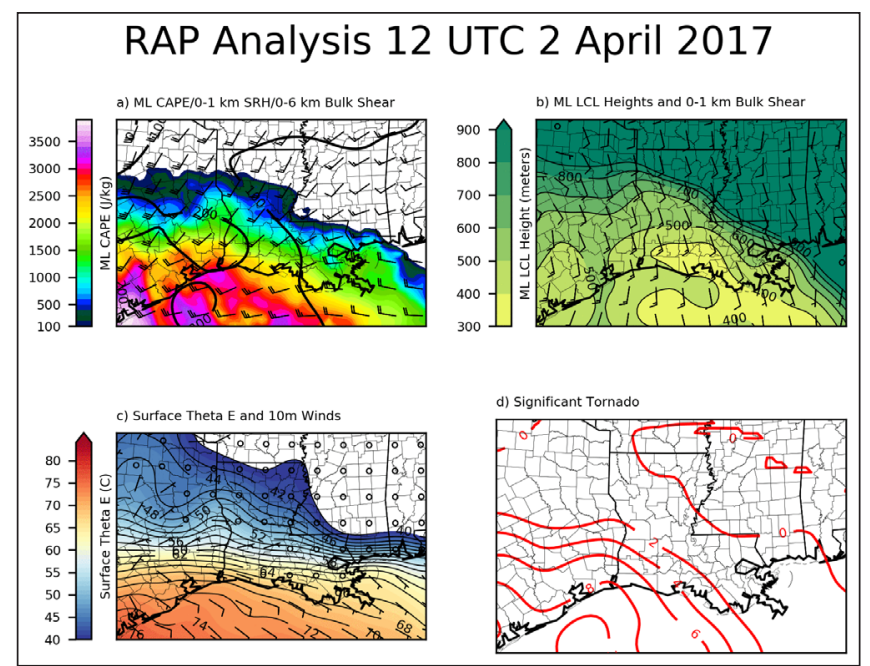

Figure 11. a). MLCAPE $\mathrm{J} / \mathrm{kg}$ (shaded), 0-1 km SRH (black contours), 0-6 km bulk shear barbs $(\mathrm{m} / \mathrm{s})$. b). MLLCL heights (shaded and black contours) and 0-1 km shear barbs $(\mathrm{m} / \mathrm{s})$. c). Equivalent potential temperature (shaded and contours) and $10 \mathrm{~m}$ wind barbs $(\mathrm{m} / \mathrm{s})$. d). Significant tornado parameter (red contours). Black triangles represent tornado locations. Click for animation.

shear values around $15 \mathrm{~m} / \mathrm{s}(\sim 30 \mathrm{kt})$ (Fig 11b). Figure $11 \mathrm{c}$ shows surface equivalent potential temperature (ThetaE) (used to visualize the associated warm front), was oriented west to east along southern Louisiana at 14 UTC. The first two tornadoes occurred along or slightly south of the warm frontal boundary. At the time of the first two tornadoes in Lafayette Parish, the STP over the area was around 6 with the highest STP values located to the south and west (Fig. 11d). Tornadic activity then diminished until the afternoon hours.

Around 19 UTC, as the surface trough elongates meridionally, there is an increase in the observed surface winds (Fig. 12). The surface winds in the warm sector increase from $10-15 \mathrm{~m} / \mathrm{s}(\sim 20-30 \mathrm{kt})$ to $15-20 \mathrm{~m} / \mathrm{s}$ $(\sim 30-40 \mathrm{kt})$. The increase in low-level southerly winds in the warm sector appears to intensify the mesoscale environment, as convection in the warm sector would produce 17 tornadoes over the following four hours between 19 and 23 UTC. MLCAPE values in central Louisiana ranged from $1500-2500 \mathrm{~J} / \mathrm{kg}$ over this time period with $200-300 \mathrm{~m}^{2} / \mathrm{s}^{2}$ of $0-1 \mathrm{~km} \mathrm{SRH}$ and $25-35 \mathrm{~m} / \mathrm{s}(\sim 50-70 \mathrm{kt})$ of bulk shear. The tornadoes that occurred during this time period also occurred in regions where the MLLCL heights were around or below $500 \mathrm{~m}$. We also notice from Fig. 11c that the warm front rapidly advanced to northern Louisiana between 15-00 


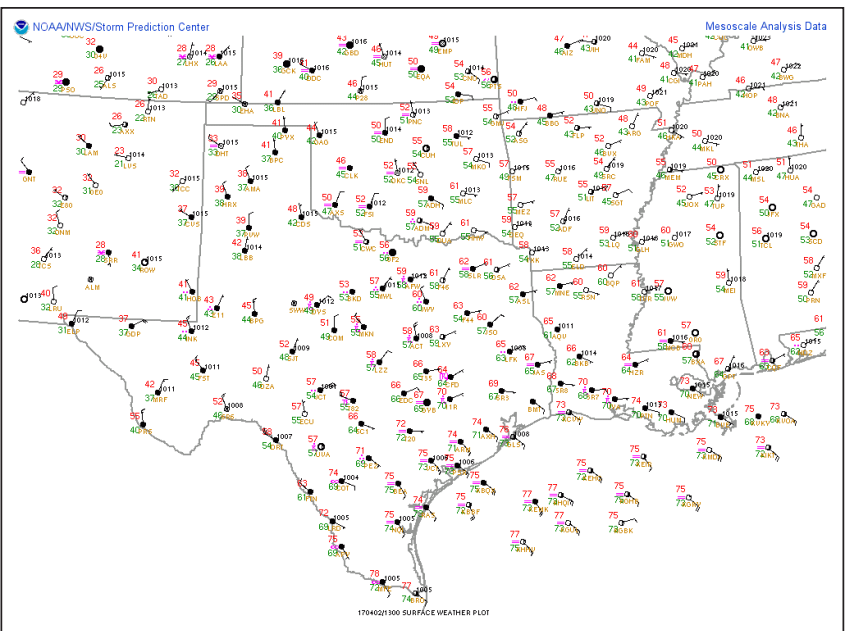

Figure 12. Surface observation plots. 13 UTC 2 April 00 UTC 3 April 2017. Click for animation.

UTC. STP values ranged anywhere from $6-10$ in the regions where the outbreak occurred, and the highest STP values remained to the southwest. The final two tornadoes occurred during the overnight hours around 9 UTC as a quasi-linear convective system advanced through extreme southeastern Louisiana.

The mesoscale environment of 2 April 2017 had similar characteristics to tornado outbreaks that have been studied in previous literature. Though this environment was common for a tornado outbreak, the magnitude of this event was uncommon for both Louisiana and the surrounding region. Therefore, we investigated how anomalous the combination of CAPE and shear was for Louisiana and the surrounding region. AF18 used a kernel density estimate (KDE) method to characterize near-storm environments for outbreak tornadoes by geographic location. To do this they plot KDE in parameter spaces of MLCAPE versus 0-6 km shear and MLLCL versus 0-1 km SRH. Each geographic location displays a relatively unique KDE distribution with respect to each parameter space (Fig. 13).

The distribution of near-storm environments for outbreak tornadoes in the south are characterized by high deep layer shear $(\sim 30 \mathrm{~m} / \mathrm{s})$ and modest MLCAPE values $(\sim 1000 \mathrm{~J} / \mathrm{kg})$ with low MLLCLs $(500-700 \mathrm{~m})$ and a broad range of $0-1 \mathrm{~km} \mathrm{SRH}\left(100-700 \mathrm{~m}^{2} / \mathrm{s}^{2}\right)$. The near-storm environment on 2 April 2017 falls in line well with the MLLCL - 0-1 km SRH parameter space in AF18. However, 2 April 2017 appears to be an outlier in the $0-6 \mathrm{~km}$ shear-MLCAPE parameter space for tornado outbreaks that occur in the south. The $0-6$ km shear-MLCAPE parameter space for 2 April 2017
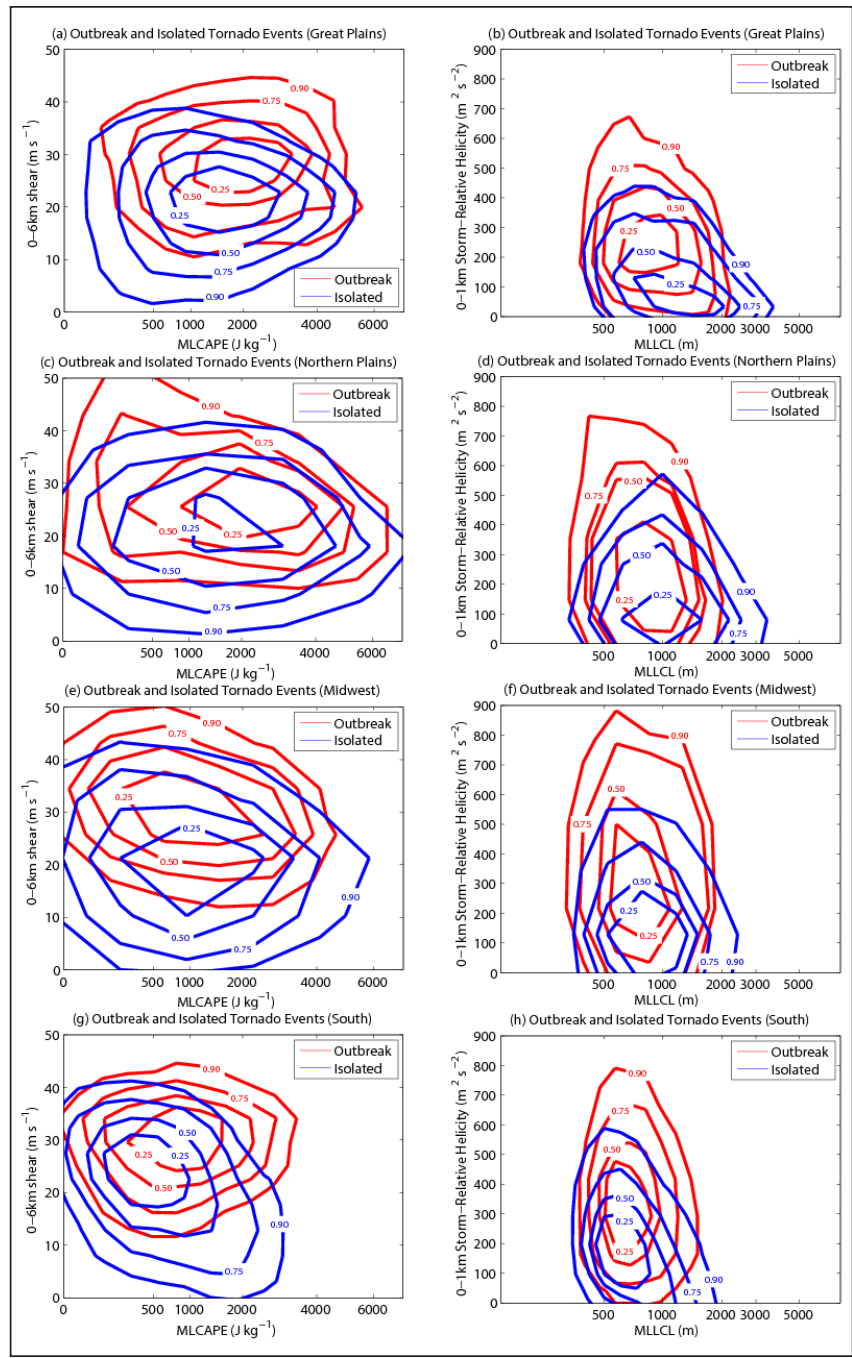

Figure 13. Figure 4 from Anderson-Frey et al. 2018. KDE plot of outbreak tornadoes (red contours) and isolated tornadoes (blue contours) for the MLCAPESHR6 (a), (c) ,(e), (g) and MLLCL-SRH1 (b), (d), (f), (h) parameter spaces for the (a),(b) Great Plains, (c), (d) Northern Plains, (e),(f) Midwest, and (g),(h) South regions. Note that MLCAPE [converted to a speed via wmax $=(2 \times \text { MLCAPE })^{1 / 2}$ is on a nonlinear scale and that MLLCL is on a logarithmic scale. A Gaussian kernel is used for KED, and contours are centered on the point of highest event density and contain $25 \%, 50 \%, 75 \%$, and $90 \%$ of the data density moving outward.

falls more in line with that of a Great Plains tornado outbreak, which is characterized by high shear (20-30 $\mathrm{m} / \mathrm{s}$ ) and high MLCAPE (1500-2500 J/kg).

The anomalous CAPE and deep layer shear observed on 2 April 2017 was not only favorable for producing a tornado outbreak, but favorable for producing an outbreak with significant tornadoes. Furthermore, the 
MLLCL heights, 0-1 SRH, and STP were favorable for significant tornadoes as well. The T03 study, which uses Rapid Update Cycle (RUC) model proximity soundings to compute these parameters, showed that thresholds of these values help in distinguishing potential for significant tornado, weak tornado, and non-tornado producing supercells. For supercells that produced significant tornadoes, MLCAPE, MLLCL, 0-1 km SRH, 0-6 km bulk shear, and STP had median values of $2150 \mathrm{~J} / \mathrm{kg}, 1004 \mathrm{~m}, 165150 \mathrm{~m}^{2} / \mathrm{s}^{2}, 25 \mathrm{~m} / \mathrm{s}(50$ $\mathrm{kt}$ ), and 2.2 respectively. Values of these parameters during the 2 April outbreak were around 1500-2500 $\mathrm{J} / \mathrm{kg}, 500-700 \mathrm{~m}, 200-300 \mathrm{~m}^{2} / \mathrm{s}^{2}, 20-30 \mathrm{~m} / \mathrm{s}(40-60$ $\mathrm{kt}$ ), and $6-10$, respectively. All of these values exceed the median values for significant tornado-producing supercells in the T03 study.

AF18 use self-organizing maps (SOM; Nowotarski and Jensen 2013; Anderson-Frey et al. 2017) to analyze the two-dimensional patterns of environments favorable for tornado outbreaks. In their analysis, 480x480 $\mathrm{km}^{2}$ maps of STP for each tornado event location are organized into nodes of distinct prototypical environments. The distribution of each node is broken down by geographic location. In the case of 2 April 2017, the two-dimensional pattern of STP with respect to each tornado in the primary outbreak location of central Louisiana can be characterized by any STP $>=1$ located to the northwest and the highest values of STP to the south. This distribution of STP is similar to that of node 8 in AF18 (see AF18 Fig. 9). Out of 169 outbreak tornadoes in this type of environment, $80 \%$ occurred in the Great Plains/Midwest, whereas the other 20\% occurred in the south. AF18 shows that this environment is more frequent in the Great Plains and Midwest.

However, AF18 define a tornado outbreak as a cluster of $>10 \mathrm{EF} 1+$ tornadoes within a 6 -h period and define all other tornado events as isolated. This differs from our definition of a tornado outbreak day as $>5$ tornadoes from 12 to 12 UTC. AF18 create SOM for isolated tornado events as well. By comparing 2 April 2017 to SOM of isolated tornado events, we provide an additional comparison to environments that may fit our definition of a typical Louisiana tornado outbreak. 2 April 2017 is similar to node 7 in the AF18 isolated event SOM (see AF18 Fig.7). Node 7 is composed of 169 isolated tornado events, all of which occurred in the Great Plains. Regardless of the outbreak definitions used, our mesoscale analysis and the aforementioned findings in AF18 lead us to believe that the environment of 2 April 2017 was more typical of an outbreak environment that would be observed in the Great Plains.

\section{Summary and conclusions}

By several climatological metrics, the 2 April 2017 tornado outbreak was an unprecedented event for the state of Louisiana. Furthermore, an event of this magnitude is uncommon for the surrounding region. The synoptic and mesoscale meteorology of this event was analyzed to determine what contributed to the anomalous nature of this event and what separated it from past tornado outbreaks in Louisiana.

The 2 April 2017 Louisiana tornado outbreak was the product of an upper-level trough centered over Texas and Mexico. The upper-level trough had a strong jet streak at its base with strong anticyclonic shear on the poleward side. An EC developed near the exit region of this jet streak with a pronounced warm front situated west to east along the southern Louisiana coast. As the upper-level trough and associated jet streak propagated eastward, the background diffluent flow associated with the anticyclonic shear in the jet streak resulted in the EC evolving with a meridionally elongated structure.

The meridionally elongated structure resulted in strong surface southerly winds that contributed to a rapid northward advancement of the associated warm front and significant moisture transport over Louisiana at the time of peak diurnal heating. This contributed to the destabilization of the environment, which produced MLCAPE values in excess of $2000 \mathrm{~J} / \mathrm{kg}$. Furthermore, the enhanced southerly flow resulted in values of $0-6$ $\mathrm{km}$ bulk shear and $0-1 \mathrm{~km}$ storm relative helicity favorable for tornadogenesis. Finally, the enhanced southerly flow and rapid northward advancement of the warm front produced significant thermal advection that supported vertical motion and widespread persistent thunderstorms in the warm sector.

Although this meteorological setup is common for tornado outbreaks, the unique element of this setup lies with respect to its geographic location. The high shear and high CAPE environment observed in central Louisiana on 2 April 2017 stands out as anomalous for this geographic area. This type of environment is more commonly associated with Great Plains tornado outbreak environments. This anomalous environment supported the development of six significant tornadoes which made the 2 April 2017 Louisiana tornado outbreak one of the largest tornado outbreaks in Louisiana history. 
Acknowledgments: We wish to thank Ryan Jewell who went above and beyond during the review process by providing us with literature, figures, animations, and data to make our revisions a much simpler process. Furthermore, we wish to thank the other two anonymous NWA reviewers and our editor Andrew Mercer for their input which helped make this paper more meaningful. We also wish to thank Alexandra Anderson-Frey for providing us with an original figure from her paper which was critical in highlighting how unique this event was.

\section{REFERENCES}

Anderson, C. J., C. K. Wilke, Q. Zhou, and J. A. Royle, 2007: Population influences on tornado reports in the United States. Wea. Forecasting, 22, 571-579, CrossRef.

Anderson-Frey, A. K., Y. P. Richardson, A. R. Dean, R. L. Thompson, and B. T. Smith, 2017: Self-organizing maps for the investigation of tornadic near-storm environments. Wea. Forecasting, 32, 1467-1475, CrossRef. , and _ 2018: Near-Storm environments of outbreak and isolated tornadoes. Wea. Forecasting, 33, 1397-1412, CrossRef.

Craven, J. P., and H. E. Brooks, 2004: Baseline climatology of sounding derived parameters associated with deep, moist convection. Nat. Wea. Dig., 28, 13-24.

Davies, H. C., C. Schër, and H. Wernli, 1991: The palette of fronts and cyclones within a baroclinic wave development. J. Atmos. Sci., 48, 1666-1689, CrossRef.

Davies-Jones, R. P., 1984: Streamwise vorticity: the origin of updraft rotation in supercell storms. J. Atmos. Sci., 41, 2991-3006, CrossRef.

Doswell, C. A., and D. W., Burgess, 1988: On Some Issues of United States Tornado Climatology. Mon. Wea. Rev., 116, 495-501, CrossRef. , R. Edwards, R. L. Thompson, J. A. Hart, and K. C. Crosbie, 2006: A simple and flexible method for ranking severe weather events. Wea. Forecasting, 21, 939-951, CrossRef.

Edwards, R., J. G. LaDue, J. T. Ferree, K. Scharfenberg, C. Maier, and W. L. Coulbourne, 2013: Tornado intensity estimation: Past, present, and future. Bull. Amer. Meteor. Soc., 94, 641-653, CrossRef.

Galway, J. G., 1977: Some climatological aspects of tornado outbreaks. Mon. Wea. Rev., 105, 477-484, CrossRef.

Garner, J. M., 2012: Environments of significant tornadoes occurring within the warm sector versus those occurring along surface baroclinic boundaries. Electronic J. Severe Storms Meteor., 7 (5), 11-28, CrossRef.
Giordano, L. A. and J. M. Fritsch, 1991: Strong tornadoes and flash-flood-producing rainstorms during the warm season in the Mid-Atlantic Region. Wea. Forecasting, 6, 437-455, CrossRef.

Grams, J. S., R. L. Thompson, D. V. Snively, J. A. Prentice, G. M. Hodges, and L. J. Reames, 2012: A climatology and comparison of parameters for significant tornado events in the United States. Wea. Forecasting, 27, 106123, CrossRef.

Hagenmeyer, B. C., 1997: Peninsular Florida Tornado Outbreaks. Wea. Forecasting, 12, 399-427, CrossRef.

Krocak, M. J. and H. E. Brooks, 2018: Climatological estimates of hourly tornado probability for the United States. Wea. Forecasting, 33, 59-69, CrossRef.

Markowski, P. M. and Y. P. Richardson, 2014: The influence of environmental low-level shear and cold pools on tornadogenesis: Insights from idealized simulations. J. Atmos. Sci., 71, 243-275, CrossRef. , J. M. Straka, and E. N. Rasmussen, 2002: Direct surface thermodynamic observations with the rear-flank downdrafts of nontornadic and tornadic supercells. Mon. Wea. Rev., 130, 1692-1721, CrossRef.

Mercer, A. E., C. M. Shafer, C. A. Doswell, L. M. Leslie, and M. B. Richman, 2009: Objective classification of tornadic and nontornadic severe weather outbreaks. Mon. Wea. Rev., 137, 4355-4368, CrossRef. , and __ 2012: Synoptic composites of tornadic and nontornadic outbreaks. Mon. Wea. Rev., 140, 2590-2608, CrossRef.

NOAA SPC, 2017: Day 1 Convective Outlook. Accessed 17 August 2017. [Available online at https://www.spc.noaa. gov/exper/archive/events/]. , 2017: Storm Prediction Center WCM Page. Accessed 17 August 2017. [Available online at https://www.spc. noaa.gov/wcm/].

Nowotarski, C. J., and A. A. Jensen, 2013: Classifying proximity soundings with self-organizing maps toward improving supercell and tornado forecast. Wea. Forecasting, 28, 783-801, CrossRef.

Pautz, M. E., 1969: Severe local storm occurrences, 19551967. ESSA Tech. Memo. WBTM FCST12, Washington, DC, $77 \mathrm{pp}$.

Rasmussen, E. N., and D. O. Blanchard, 1998: A baseline climatology of sounding-derived supercell and tornado forecast parameters. Wea. Forecasting, 13, 1148-1164, CrossRef.

Rogers, J. W., B. A. Hagenhoff, A. E. Cohen, R. L. Thompson, B. T. Smith, E. E. Carpenter, 2016: Lower Mississippi River Valley Quasi-Linear Convective System Tornado Environments and Radar Signatures. J. Operational Meteor., 5 (4), 42-52, CrossRef.

Rotunno, R., and J. B. Klemp 1982: The influence of shearinduced pressure gradient on thunderstorm motion. Mon. Wea. Rev., 110, 136-151, CrossRef. 
Schultz, D. M., and F. Zhang, 2007: Baroclinic Development within zonally-varying flows. Quart. J. Roy. Meteor. Soc., 133, 1101-1112, CrossRef.

, D. Keyser, and L. F. Bosart, 1998: The effect of largescale flow on low-level frontal structure and evolution in mid-latitude cyclones. Mon. Wea. Rev., 126, 1767-1791, CrossRef.

Schumacher, R. S., D. M. Schultz, and J. A. Knox, 2010: Convective snowbands downstream of the Rocky Mountains in an environment with conditional, dry symmetric, and inertial instabilities. Mon. Wea. Rev., 138, 4416-4438, CrossRef.

Shaefer, J. T. and R. Edwards, 1999: The SPC tornado/severe thunderstorm database. Preprints, 11th Conf. on Applied Climatology, Dallas, TX, Amer. Meteor. Soc., 603-606.

Simmons, K. M. and D. Sutter, 2011: Economic and Societal Impacts of Tornadoes. Amer. Meteor. Soc., 282 pp., CrossRef.

Thompson, R. L., 1998: Eta model storm-relative winds associated with tornadic and nontornadic supercells. Wea. Forecasting, 13, 125-137, CrossRef.

, and M. D. Vescio, 1998: The destruction potential index-A method for comparing tornado days. Preprints, 19th Conf. on Severe Local Storms, Minneapolis, MN, Amer. Meteor. Soc., 280-282.

R. Edwards, J. A. Hart, K. L. Elmore, and P. Markowski, 2003: Close proximity soundings within supercell environments obtained from the rapid update cycle. Wea. Forecasting, 18, 1243-1261, CrossRef.

Tochimoto, E. and H. Niino, 2016: Structural and environmental characteristics of extratropical cyclones that cause tornado outbreaks in the warm sector: A composite study. Mon. Wea. Rev., 144, 945-969, CrossRef.

Verbout, S. M., H. E. Brooks, L. M. Leslie, and D. M. Schultz, 2006: Evolution of the U.S. tornado database: 19542003. Wea. Forecasting, 21, 86-93, CrossRef.

Wernli, H., R. Fehlmann, and D. Lüthi, 1998: The effect of barotropic shear on upper-level induced cyclogenesis: Semigeostrophic and primitive equation numerical simulations. J. Atmos. Sci., 55, 2080-2094, CrossRef. 